\title{
Erosion Wear of Axial Flow Impellers in a Solid-liquid Suspension
}

I. Fořt, J. Medek, F. Ambros

A study was made of the erosion wear of the blades of pitched blade impellers in a suspension of waste gypsum from a thermal power station (vol. concentration $C_{V}=18.3 \%$, particle mean diameter $d=0.1 \mathrm{~mm}$, degree of hardness "2.5") and silicious sand $\left(C_{V}=10 \%\right.$, $d=0.4 \mathrm{~mm}$, degree of hardness "7.5") in water under a turbulent flow regime of agitated charge when complete homogeneity of the suspension was achieved. Experiments were carried out on pilot plant mixing equipment made of stainless steel (diameter of cylindrical vessel $T=390 \mathrm{~mm}$, diameter of impeller $D=100 \mathrm{~mm}$, impeller off-bottom clearance $h=100 \mathrm{~mm}$ ) equipped with four wall radial baffles (width $b=39 \mathrm{~mm}$ ) and an impeller with four inclined plane blades (pitch angle $\alpha=20^{\circ}, 30^{\circ}$, 45 , relative blade width W/D $=0.2$ ) made either of rolled brass (Brinell hardness 40-50 BH) or of structural steel (Brinell hardness 100-120 BH) always pumping the liquid downwards towards the flat vessel bottom. Two erosion process mechanisms appear, depending on the hardness of the solid particles in the suspension: while the particles of gypsum (lower hardness) generate a uniform sheet erosion over the whole surface of the impeller blade, the particles of silicious sand (higher hardness) generate wear of the leading edge of the impeller blades, together with a reduction of the surface of the worn blade. The hardness of the impeller blade also affects the rate of the erosion process: the higher the hardness of the impeller blade, the lower the wear rate of the blade. This study consists of a description of the kinetics of the erosion process of both mechanisms in dependence on the pitch angle of the tested impellers. While the wear of the leading edge of the blade exhibits a monotonous dependence on the pitch angle, the sheet erosion exhibits the maximum rate within the interval of the pitch angles tested $\alpha \in\left\langle 20^{\circ} ; 45^{\circ}\right\rangle$. However, generally the pitch angle $\alpha=45^{\circ}$ seems to be the most convenient angle of blade inclination when both investigated mechanisms of the blade erosion process are considered at their minimum rate.

Keywords: pitched blade impeller, erosion wear, solid-liquid suspension.

\section{Introduction}

In all areas of particulate technology where powders are handled, structures in contact with the powder will exhibit wear. In some applications this wear may be so severe as to limit the life of a component or plant, while in others it may be negligible. All particles will cause some wear, but in general the harder they are, and the more angular in shape, the more severe will be the wear [1].

Mixing processes including the suspension of solids in liquids have shown that the rate at which the impeller wears is a strong function of the impeller blade inclination angle (pitch angle) as well as the impeller tip speed [2]. The impact rate of the solid particles affecting the blade of the pitched blade impellers was studied experimentally with the aim of explaining the significant dependency of impact rate on impeller tip speed and impeller diameter [3, 4]. The impact mostly occurs in the outer and upper corners of the blades for a pitched blade impeller pumping downwards. This fact corresponds to the results of experimental studies $[5,6]$ investigating the erosive wear of pitched blade impellers in a highly erosive suspension, where the impeller blade leading edge is worn, together with a reduction of the surface blade. Then, e.g., the impeller pumping capacity decreases.

This study deals with an attempt to express mathematically the shape of the worn blade of a pitched blade impeller in two sorts of industrial suspension, i.e., in a suspension of flue gas desulphurization product (gypsum) and a suspension of silicious sand, and to interpret the influence of the impeller erosion wear on the surface or on the thickness of the worn blade of the various pitch angles under its erosion process.

\section{Experimental}

Experiments were carried out on pilot plant mixing equipment (see Fig. 1), with water as a working liquid and two types of solid phases:

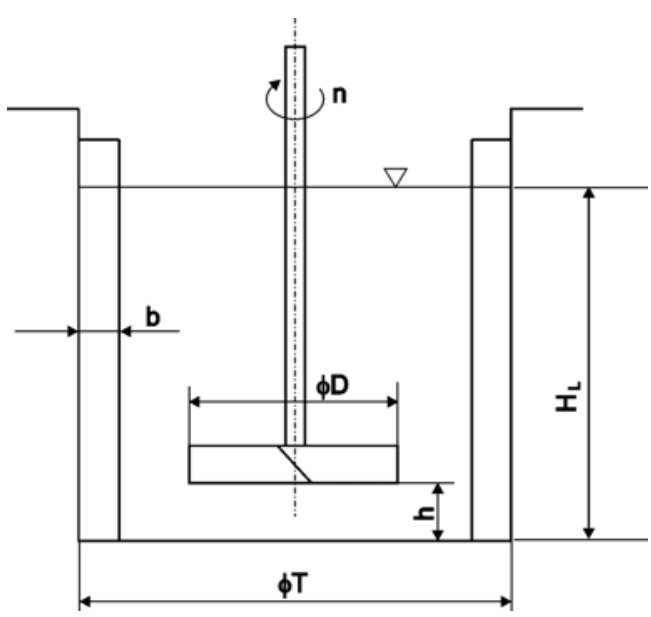

Fig. 1: Geometry of pilot plant mixing equipment

$(H=T=290 \mathrm{~mm}, h=D=100 \mathrm{~mm}$, four baffles, $b / T=0.1)$

1. silicious sand (volumetric concentration $C_{V}=10 \%$ vol., mean diameter of particles $d=0.4 \mathrm{~mm}$ ),

2. waste gypsum $\left(\mathrm{CaSO}_{4} \cdot 2 \mathrm{H}_{2} \mathrm{O}\right)$ from a thermal power station $\left(C_{V}=18.3 \%\right.$ vol., $\left.d=0.1 \mathrm{~mm}\right)$ after a desulphurization process.

Pitched blade impellers with four adjustable inclined plane blades (see Fig. 2) made of rolled brass or construction steel were used for the erosion tests. As an independent variable we took a pitch angle $\alpha$ of the impeller with inclined plane blades, and in all cases the frequency of the impeller revolution, $n$, was kept constant under conditions of complete homogeneity of the suspension. For the experiments we used a cylindrical metal baffled vessel made of stainless steel (see Fig. 1). 
During the experiments with silicious sand the shape of the blade profile was determined visually from magnified

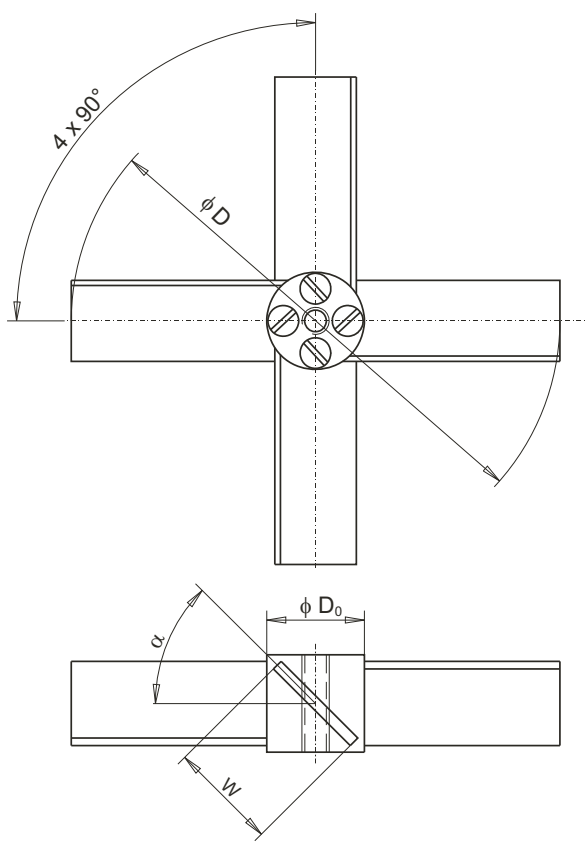

Fig. 2: Design of a pitched blade impeller with four inclined plane adjustable blades $\left(D=100 \mathrm{~mm}, D_{0}=25 \mathrm{~mm}\right.$, $W=20 \mathrm{~mm}, s=1.2+0.04 \mathrm{~mm}$ (experiments with silicious sand), $s=1.0+0.04 \mathrm{~mm}$ (experiments with waste gypsum), $\left.\alpha=15^{\circ}, 20^{\circ}, 30^{\circ}, 45^{\circ}, n_{1}=479 \mathrm{RPM}, n_{2}=640 \mathrm{RPM}\right)$

copies of the worn impeller blades on photosensitive paper (magnification ratio: approx. 2:1). The average course of the blade profile for the given length of the erosion process was determined as an average curve from four individual worn impeller blades. The surface of the worn blades was determined from their magnified copies using a planimeter.

During the experiments with waste gypsum the local thickness of the blade $s_{i, j}(j=1,2,3,4)$ along the blade length (see Fig. 3) was determined by means of a contact micrometer with an accuracy $\pm 0.01 \mathrm{~mm}$. The erosion process when a suspension of waste gypsum was used exhibits no change in

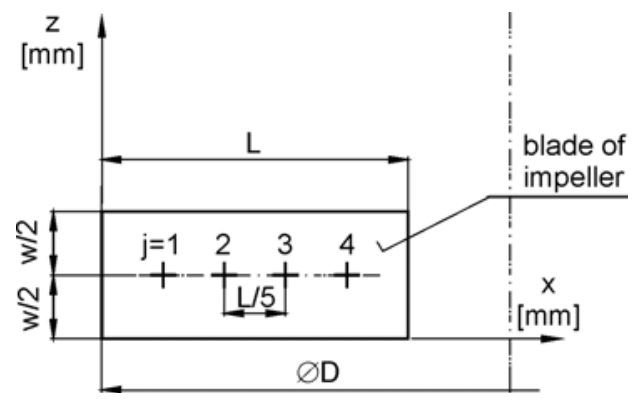

Fig. 3: Distribution of measurement points for determining of the local blade thickness along the blade length the blade profile, e.g., at its leading edge. Only its thickness changes.

\section{Results and Discussion}

Two series of experiments were evaluated: studies of the erosion wear of the impeller blades under the influence of particles of silicious sand (higher hardness) and under the influence of waste gypsum (lower hardness).

\section{Axial impeller in a suspension of silicious sand}

During the erosion process of the pitched blade impeller caused by solid particles of silicious sand, its metal plane blade changes shape mainly around its leading edge [6]. The radial profile of the worn plane blade can be considered in dimensionless exponential form (see Fig. 4):

$$
H(X)=1-C \exp [k(1-X)] \text {, }
$$

where the dimensionless axial (vertical) coordinate along the width of the blade is

$$
H=\mathrm{z}(x) / W
$$

and the dimensionless longitudinal (radial) coordinate along the radius of the blade is

$$
X=2 x / D \text {. }
$$

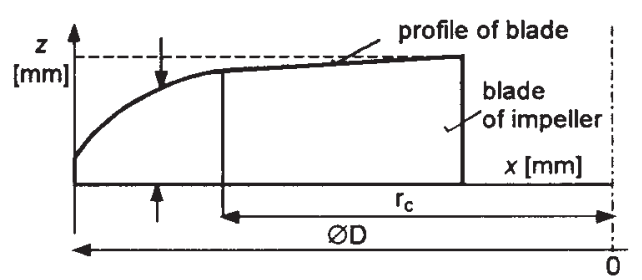

Fig. 4: Radial profile of the leading edge of the worn blade of a pitched blade impeller

The values of the parameters of Eq. (1) - the wear rate constant $k$ and the geometric parameter of the worn blade $C$ - were calculated by the least squares method from the experimentally found profile of the worn blade; each curve was calculated from $14-16$ points $(X, H)$ with a regression coefficient better than $R=0.970$.

Figs. 5 and 6 show the dependence (all the dependences mentioned here were calculated from experimental data by the least squares method) of the wear rate constant $k$ on the duration of erosion process $t$ for the given impeller pitch angle $\alpha$ both for rolled brass and for construction steel. The independence of the wear rate constant from the duration of the erosion process proves the reliability of the chosen analytical function [1] describing the radial profile of the worn blade. Nevertheless, parameter $k$ depends significantly on the pitch angle: the lower the pitch angle, the higher the rate of the erosion process of the pitched blade impeller. This result is in excellent accordance with the fact (1) that metals tend to suffer the most severe erosion wear at impact angles of $20^{\circ}$ to $30^{\circ}$ (measured from the plane of the blade surface), i.e., the angles at which the particles strike the blade surface.

Figs. 7 and 8 show the dependence of the worn blade geometric parameter $C$ on quantity $T$. For both tested metals this parameter is linearly dependent on the duration of the 


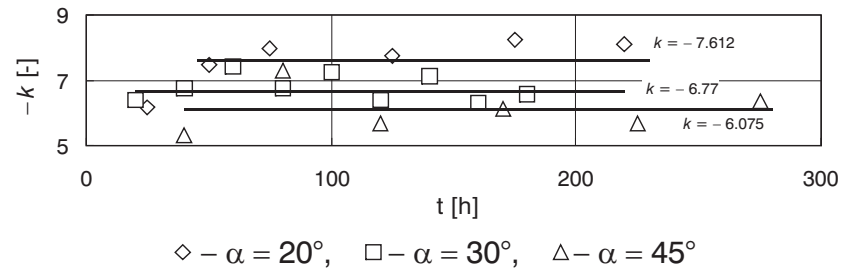

Fig. 5: Dependence of the wear rate constant on the duration of the erosion process (impeller blades made of rolled brass)

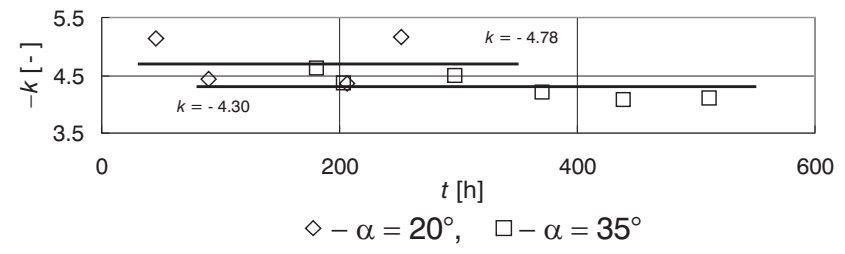

Fig. 6: Dependence of the wear rate constant on the duration of the erosion process (impeller blades made of construction steel)

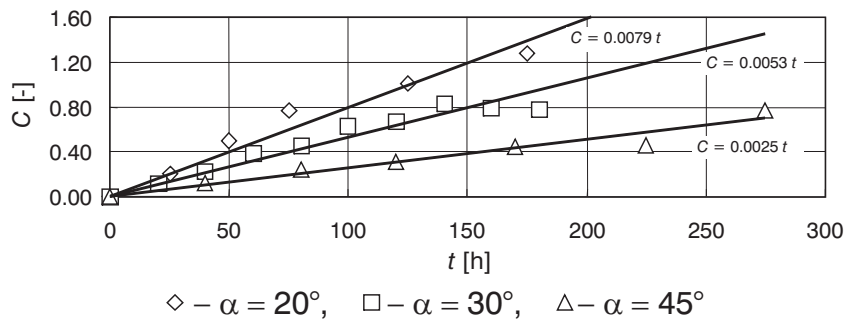

Fig. 7: Dependence of the worn blade geometric parameter on the duration of the erosion process (impeller blades made of rolled brass)

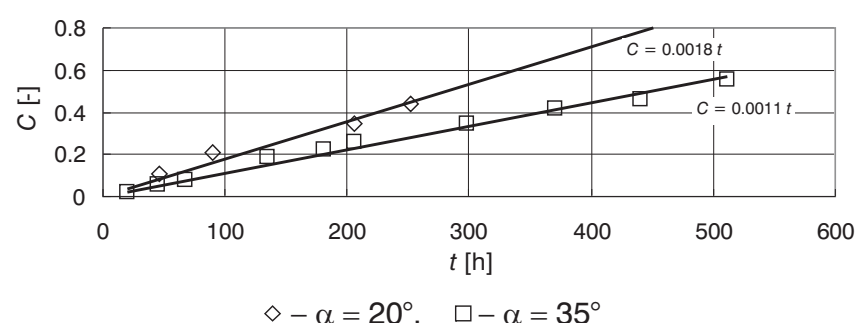

Fig. 8: Dependence of the worn blade geometric parameter on the duration of the erosion process (impeller blades made of construction steel)

process. This course confirms fairly well the strong dependence of the studied erosion wear on its duration. Moreover, this is in accordance with the experimentally determined distribution of the rate of particle impact along the blade of the pitched blade impeller indicated on the artificially soft surface of the impeller blades (4).

Figures 9 and 10 illustrate the dependences of the experimental parameters of function (1) on the impeller pitch angle. The linear form for the two tested metals

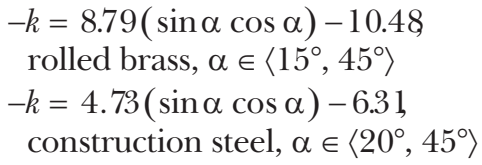

characterizes the relation between the erosion wear of the impeller blade and the corresponding (axial) component

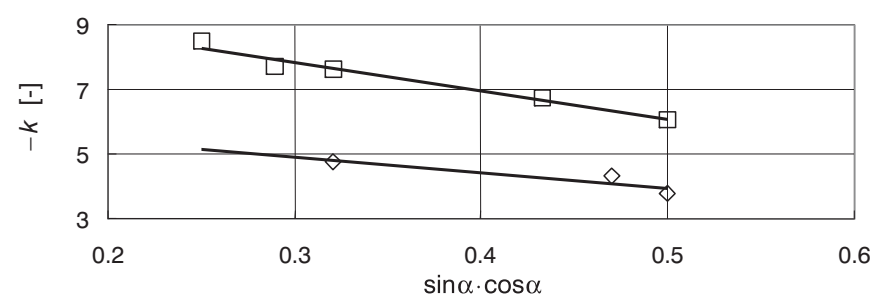

$\diamond$ - rolled brass: $\alpha \in\left\langle 15^{\circ}, 20^{\circ}\right\rangle, \square-$ construction steel: $\alpha \in\left\langle 20^{\circ}, 45^{\circ}\right\rangle$

Fig. 9: Dependence of the wear rate constant on the impeller pitch angle

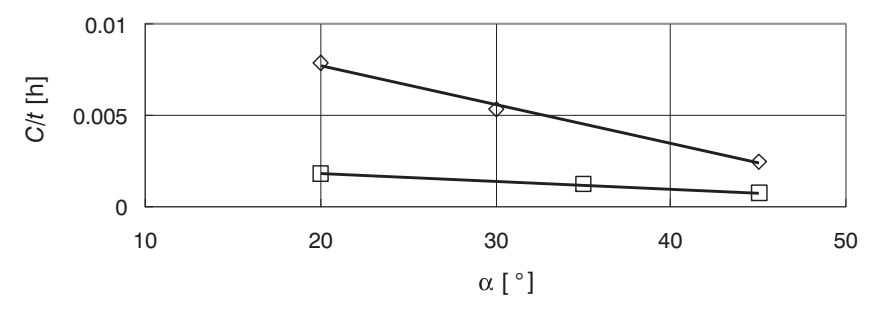

$\diamond-$ rolled brass: $\alpha \in\left\langle 20^{\circ}, 45^{\circ}\right\rangle, \square-$ construction steel: $\alpha \in\left\langle 20^{\circ}, 45^{\circ}\right\rangle$

Fig. 10: Dependence of the worn blade geometric parameter on the impeller pitch angle

of the mean velocity in the discharge stream leaving a pitched blade impeller [5] expressed by means of the product $\sin \alpha \cos \alpha$. At the same time our results confirm the general view of the relation between the hardness of the worn metal and its wear rate: the higher the hardness of the worn metal, the lower its wear rate.

The linear forms

$$
\begin{aligned}
& C / t=-2.14 \cdot 10^{-4} \alpha+1.21 \cdot 10^{-2}, \\
& \text { rolled brass, } \alpha \in\left\langle 20^{\circ}, 45^{\circ}\right\rangle \\
& C / t=-0.41 \cdot 10^{-4} \alpha+0.27 \cdot 10^{-2}, \\
& \text { construction steel, } \alpha \in\left\langle 20^{\circ}, 45^{\circ}\right\rangle
\end{aligned}
$$

characterize the fact that the geometric parameter of the profile of a worn blade $C$ depending on the duration of the erosion period corresponds to the development of the exponential profile of the worn blade with increasing time $T$. Similarly as for parameter $k$ the geometric parameter of the profile of the worn blade exhibits lower values for construction steel (Brinell hardness 100-120 HB) than for rolled brass (Brinell hardness 40-50 HB).

Figs. 11 and 12 illustrate the dependence of the surface of the impeller worn blade $A_{\text {worn }}$ (related to the unworn blade surface $\mathrm{A}_{0}$ ) on the duration of the erosion process for both rolled brass and construction steel impeller blades as well as being compared with predicted values [6]. The rate of the blade surface reduction can be expressed in linear form of the found dependence, i.e., for rolled brass:

$$
\begin{aligned}
& A_{\text {wor }} / A_{0}=1-0.0014 t, \alpha=20^{\circ}, \\
& A_{\text {worn }} / A_{0}=1-0.0008 t, \alpha=45^{\circ},
\end{aligned}
$$


and for construction steel:

$$
\begin{aligned}
& A_{\text {worn }} / A_{0}=1-0.0004 t, \alpha=20^{\circ}, \\
& A_{\text {worn }} / A_{0}=1-0.0003 t, \alpha=35^{\circ} .
\end{aligned}
$$

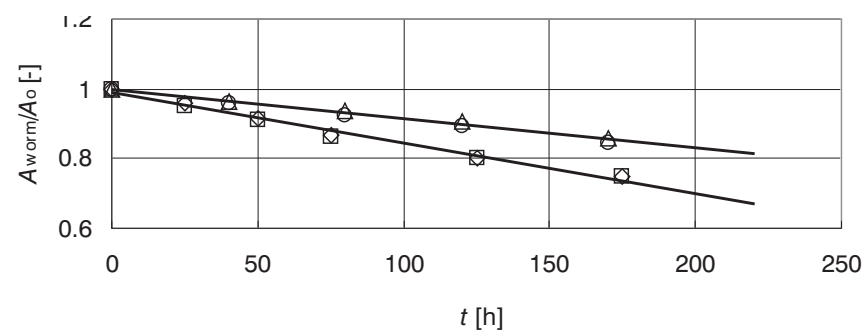

$\alpha=20^{\circ}: \diamond$-theoretically predicted values, $\square$-experimental values $\alpha=45^{\circ}: \Delta-$ theoretically predicted values, $O$ - experimental values

Fig. 11: Dependence of the surface of the worn blade on the duration of the erosion process - impeller blades made of rolled brass

All the above mentioned relations express the complex influence of the duration of the erosion process and the hard-

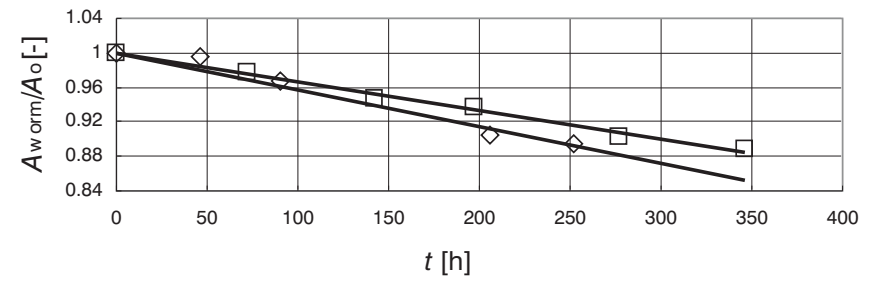

$$
\square-\alpha=20^{\circ}, \diamond-\alpha=35^{\circ}
$$

Fig. 12: Dependence of the surface of the worn blade on the duration of the erosion process - impeller blades made of construction steel

ness of the impeller blade on the rate of its surface reduction, i.e., the positive effect of both the increase of the impeller pitch angle and the increase of the metal hardness on the rate of the blade erosion wear. As follows from Fig. 11, the proposed model of the erosion wear of pitched blade impellers (see Eq. 1) enables us to make a sufficiently accu- rate theoretical calculation of the rate of the surface blade reduction [6].

\section{Axial impeller in a suspension of waste gypsum}

During the erosion process when a suspension of the waste gypsum was used, no change of the blade profile was observed, and only its thickness was changed. Then for the given duration of erosion period $t$ the average thickness of the blade was calculated (see Fig. 3)

$$
s_{i}=\frac{1}{4} \sum_{j=1}^{4} s_{i, j}
$$

as well as its standard deviation

$$
\sigma_{s_{i}}=\frac{1}{3}\left[\sum\left(s_{i}^{2}-s_{i, j}^{2}\right)\right]
$$

and, finally, the relative change of the average blade thickness for the given moment of the erosion process was determined

$$
\frac{\Delta s_{i}}{s_{0}}=\frac{s_{0}-s_{i}}{s_{0}}
$$

where $s_{0}$ is the initial average thickness of the unworn blade.

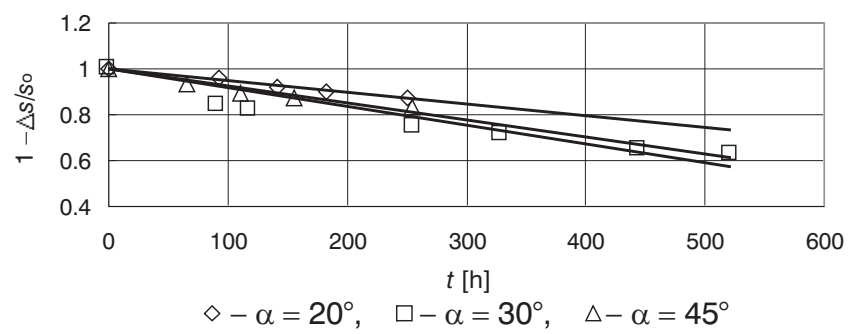

Fig. 13: Dependence of relative blade thickness on the duration of the erosion process - impeller blades made of rolled grass

Table 1 and Fig. 13 illustrate the dependence of quantity $\Delta s_{i} / s_{0}$ on the duration of the erosion process. The values of quantity $\sigma_{s i}$ confirm that the uniform sheet erosion of the impeller blade can be considered for both metals tested when waste gypsum from the thermal power station is used. Its degree of hardness exhibits quite a different effect on the

Table 1. Dependence of blade thickness on duration of the erosion process

I. Impeller made of rolled brass

$\alpha=20^{\circ}$
\begin{tabular}{|l|c|c|c|c|c|}
\hline$t[\mathrm{~h}]$ & 0 & 93 & 141 & 183 & 241 \\
\hline $\bar{s}_{i}[\mathrm{~mm}]$ & 1.020 & 0.9780 & 0.9400 & 0.9200 & 0.8900 \\
\hline$\sigma_{s i}[\mathrm{~mm}]$ & 0 & 0.02062 & 0.015 & 0.02062 & 0.03162 \\
\hline$\Delta \mathrm{s}_{i} / \bar{s}_{0} \cdot 100[\%]$ & 0 & 4.2 & 7.8 & 9.8 & 12.5 \\
\hline
\end{tabular}

$\alpha=30^{\circ}$

\begin{tabular}{|l|c|c|c|c|c|c|c|}
\hline$t[\mathrm{~h}]$ & 0 & 91 & 118 & 256 & 329 & 444 & 521 \\
\hline $\bar{s}_{i}[\mathrm{~mm}]$ & 1.040 & 0.870 & 0.850 & 0.780 & 0.740 & 0.670 & 0.640 \\
\hline$\sigma_{s i}[\mathrm{~mm}]$ & 0 & 0.01414 & 0.01732 & 0.03109 & 0.0216 & 0.02828 & 0.01915 \\
\hline$\Delta \mathrm{s}_{i} / \bar{s}_{0} \cdot 100[\%]$ & 0 & 16.3 & 18.2 & 25.4 & 28.8 & 35.6 & 37.0 \\
\hline
\end{tabular}




$\alpha=45^{\circ}$
\begin{tabular}{|l|c|c|c|c|c|}
\hline $\mathrm{t}[\mathrm{h}]$ & 0 & 66 & 111 & 155 & 254 \\
\hline $\bar{s}_{i}[\mathrm{~mm}]$ & 1.030 & 0.960 & 0.920 & 0.900 & 0.860 \\
\hline$\sigma_{s i}[\mathrm{~mm}]$ & 0 & 0.0238 & 0.0245 & 0.0294 & 0.02986 \\
\hline$\Delta \mathrm{s}_{i} / \bar{s}_{0} \cdot 100[\%]$ & 0 & 6.8 & 10.7 & 12.6 & 16.5 \\
\hline
\end{tabular}

II. Impeller made of construction steel

$\alpha=45^{\circ}$
\begin{tabular}{|l|c|c|c|c|c|}
\hline$t[\mathrm{~h}]$ & 0 & 50 & 93 & 163 & 235 \\
\hline $\bar{s}_{i}[\mathrm{~mm}]$ & 1.0400 & 1.0275 & 1.0275 & 1.0250 & 1.0250 \\
\hline$\sigma_{s i}[\mathrm{~mm}]$ & 0 & 0.00957 & 0.00957 & 0.00577 & 0.00577 \\
\hline$\Delta \mathrm{s}_{i} / \bar{s}_{0} \cdot 100[\%]$ & 0 & 1.2 & 1.2 & 1.44 & 1.44 \\
\hline
\end{tabular}

metal surface than previously used silicious sand with degree of hardness approx. three times greater than the first one. It can be proposed: the different mean particle diameters of the two powders under study need not affect the erosion mechanism [1], i.e., their differences are caused only via their different hardnesses.

The relative change of the average blade thickness $\Delta s_{i} / \bar{s}_{0}$ depends both on the type of metal and on the blade pitch angle $\alpha$. According with the above mentioned results, when silicious sand was used the blade made of construction steel exhibits a lower erosion rate than the blade made of rolled brass. The dependence of the quantity $\Delta s_{i} / \bar{s}_{0}$ on the duration of the erosion process can be expressed in linear form

$$
\begin{aligned}
& \Delta s_{i} / \bar{s}_{0}=1-0.0005 t, \alpha=20^{\circ}, \\
& \Delta s_{i} / \bar{s}_{0}=1-0.0008 t, \alpha=30^{\circ}, \\
& \Delta s_{i} / \bar{s}_{0}=1-0.0007 t, \alpha=45^{\circ} .
\end{aligned}
$$

The shape of relation $\Delta s_{i} / \bar{s}_{0}=\mathrm{f}(t)$ does not exhibit a monotonous dependence on the impeller pitch angle as in the case of the harder powder used previously, and we can consider the maximum rate of the erosion process when the impeller blade pitch angle $\alpha=30^{\circ}$. It follows from the above results that more tests with various powders with different particle hardnesses should be made, in order to gain better and fuller evidence of the influence of solid particles on the rate of erosion of pitched blade impellers.

\section{Conclusions}

Two mechanisms of the erosion process of pitched blade impellers in a solid-liquid suspension were found in this study:

a) particles of waste gypsum (lower hardness) generate uniform sheet erosion over the whole surface of the impeller blade,

b) particles of silicious sand (higher hardness) generate predominantly erosion wear of the leading edges of the impeller blade.

The higher the hardness of the impeller blade material, the lower the wear rate of the blade.

While the wear rate of the blade leading edge exhibits a monotonous dependence on the impeller pitch angle, sheet erosion exhibits the maximum rate within the interval of the pitch angles tested $\alpha \in\left\langle 20^{\circ}, 45^{\circ}\right\rangle$.

The impeller pitch angle $\alpha=45^{\circ}$ seems to be the most convenient angle of plane blade inclination when the two investigated mechanisms of the blade erosion exhibit their minimum rate.

All the results mentioned are valid for turbulent regime of flow agitated charge.

\section{List of Symbols}

A dimensionless surface of impeller blade $(A=A / W(D / 2))$

a surface of impeller blade, $\mathrm{m}^{2}$

$b \quad$ baffle width, $m$

C geometric parameter of the profile of a worn blade

$C_{V} \quad$ volumetric concentration, $\mathrm{m}^{3} / \mathrm{m}^{3}$

$D \quad$ impeller diameter, $\mathrm{m}$

$D_{0} \quad$ hub diameter, $\mathrm{m}$

$d \quad$ particle diameter, $\mathrm{m}$

$H$ dimensionless axial coordinate of the profile of worn blade

$H_{L} \quad$ height of liquid from bottom of vessel, m

$h \quad$ off bottom impeller clearance, $\mathrm{m}$

$k \quad$ wear rate constant

$n \quad$ impeller frequency of revolution, $\mathrm{s}^{-1}$

$R \quad$ regression coefficient

$s \quad$ thickness of impeller blade, $\mathrm{m}$

$t$ time, $\mathrm{h}$

$W \quad$ width of impeller blade, $\mathrm{m}$

$X \quad$ longitudinal coordinate of impeller blade, $\mathrm{m}$

$z \quad$ axial (vertical) coordinate along the width of the blade, $\mathrm{m}$

$\alpha \quad$ pitch angle of blade, ${ }^{\circ}$

$\sigma \quad$ standard deviation

\section{Subscripts and superscripts}

i summation index

j summation index

o initial value

worn worn

- average value 
This research has been supported by the Research Project of the Ministry of Education of the Czech Republic J04/98: 212200008.

\section{REFERENCES}

[1] Hutchings, I. M.: Wear by particulates. Chem. Eng. Sci., 1987, 42, No. 4, pp. 869-878

[2] Kipke, K.: Erosiver Verschleiss von Rührorganen. Chem.Ing.- Tech., 1980, 52, pp. 658-659

[3] He, Y., Takahashi, K., Nomura, T.: Particle impeller impact for a six bladed $45^{\circ}$ pitched blade impeller in an agitated vessel. J. Chem. Eng. Jap., 1995, 28, No. 6, pp. 786-789

[4] Kee, K. C., Reilly, C. D.: An experimental method for obtaining particle impact frequencies and velocities on impeller blades. Proceedings of the $10^{\text {th }}$ European Conference on Mixing, Delft (The Netherlands), Editors: H. E. A. van den Akker, J. J. Derksen, Elsevier, Amsterdam 2000, pp. 231-238
[5] Fořt, I., Ambros, F., Medek, J.: Study of wear and tear of axial flow impellers. Proceedings of the Fluid Mixing VI Conference (Editor: H. Benkreira), Bradford (England) 1999, pp. 59-68

[6] Fořt, I., Ambros, F., Medek, J.: Study of wear of pitched blade impellers. Acta Polytechnica 2000, 40, No. 516, pp. 5-10

Doc. Ing. Ivan Fořt, DrSc.

Ing. František Ambros, Csc.

Dept. of Process Engineering

Czech Technical University in Prague

Faculty of Mechanical Engineering

Technická 4, 16607 Praha 6

Prof. Ing. Jaroslav Medek, Csc.

Dept. of Process Engineering

Technical University

Faculty of Mechanical Engineering

Technická 2, 61669 Brno 